\title{
A tribute to Professor Dr. med. Dipl. Psych. Andreas Warnke
}

\author{
Peter Riederer
}

Received: 15 March 2010/ Accepted: 15 March 2010/Published online: 26 March 2010

(C) Springer-Verlag 2010

Although Andreas Warnke is going to retire soon, this would not be the impression if you would meet him and talk to him about common interests. Open minded, future orientated, family based and devotion for his patients/kids are the prime characteristics and everyone who meets Andreas Warnke is impressed by his enormous engagement for his young patients and the empathy in handling the often hard and complicated jobs. Patients, relatives and co-workers regard him as a friend and someone who can be trusted to do his very best in any situation.

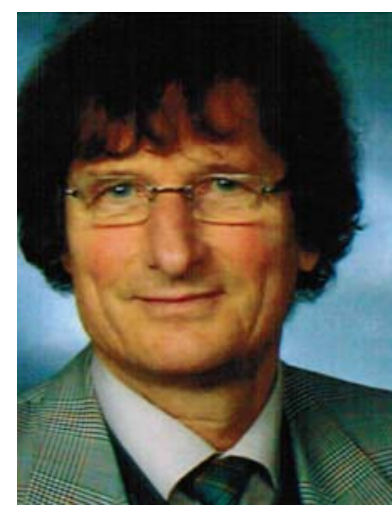

Andreas Warnke

I was lucky enough to meet Andreas soon after he took over the chairmanship of the Clinic and Polyclinic of Child and Youth Psychiatry, Psychosomatics and Psychotherapy

\footnotetext{
P. Riederer $(\square)$

Department of Clinical Neurochemistry, Clinic and Policlinic of Psychiatry, Psychosomatic and Psychotherapy, University of Wuerzburg, Fuechsleinstr. 15, 97080 Wuerzburg, Germany e-mail: peter.riederer@mail.uni-wuerzburg.de
}

at the Medical School of the University of Wuerzburg, Germany, in 1991. After having further developed this highly renowned department based on his widespread scientific interests including neurobiological and neuropsychological correlates of psychic disturbances, his interest in clinical follow-up studies, his research into psychotherapeutic aspects of ADHD, anorexia nervosa and anxiety, his work on the genetic basis of psychiatric behaviours and therapeutic drug monitoring as a strategy to optimize psychopharmacological treatment options, I offered him to lead the section Biological Child and Adolescent Psychiatry in 2003.

Since then, he successfully developed his section and he gave many important suggestions to increase manuscript submissions and to create ideas for special issues devoted to Child Psychiatry.

As President and founding member of the World Federation of ADHD (2008) and member of the German Academy of Sciences, Leopoldina (2009), he was able to give substantial input to JNT in general and to his section in particular. With begin of 2010, he wanted to step back from his duties and handed his section over to Prof. Dr. Beate Herpertz-Dahlmann, a distinguished and high calibre scientist in the field of Child and Youth Psychiatry from the University of Aachen, Germany.

I am extremely grateful for the time and work that Andreas Warnke devoted to our journal. I hereby would like to express sincere gratitude for his efforts and best wishes for the future on behalf of the entire editorial and publishing team of Springer Wien NewYork as well.

All of us will miss his help and advice and wish Andreas Warnke a bright future, good health, luck and happiness and many more excellent ideas to promote within the next years. And we welcome our new Section Editor. 